\title{
Epistemologías del sur y odontología
}

\section{Epistemology of the southern hemisphere and dentistry}

\author{
Ebingen Villavicencio-Caparó, * María Cristina Alvear-Córdova§
}

En el siglo XVI de esta era, la Malinche y Felipillo fueron personajes oriundos de México y Perú respectivamente, ambos apoyaron a los invasores españoles en sus propósitos colonizadores y representaron al personaje autóctono que prefiere lo extranjero, tal vez por una suposición de que lo foráneo es mejor que lo propio.

Las epistemologías del sur (LEDS), son un conjunto de posturas ideológicas, que han venido siendo desarrolladas en Sudamérica desde la década de los 80 , tienen como finalidad la emancipación del pensamiento, la cultura y la investigación, contraponen sus descubrimientos a la visión eurocéntrica que dominó la ciencia, la filosofía y las humanidades en general, a esta corriente se le ha llamado también el giro descolonizador.

Sergio de Zubiría, filósofo colombiano, citando a Boaventura de Santos dice: «Las historias siempre son contadas por el cazador, qué diferentes serían si fueran contadas desde la perspectiva del leopardo". ${ }^{1}$ Cita que concuerda con lo postulado por el profesor mexicano Enrique Dussel, «La justicia social global, sólo es posible si hay justicia cognitiva global». ${ }^{2}$ Esto significa que la inequidad entre el valor del conocimiento de los vencidos y de los vencedores (países colonizadores), perpetúa esta relación de desventaja, lo cual no permite la generación de justicia.

La globalización creada postguerra fría nos dejó como consecuencia, el pensamiento hegemónico de las escuelas que pertenecen a los países vencedores, con la concomitante desaparición de los saberes alternativos. Desde ese momento es válido sólo el punto de vista del vencedor, que se complementa con el deseo de aculturación de los países en desarrollo y por consiguiente, existe la percepción de que todo lo importado, que proviene de los países de «primer mundo" es mejor que lo nacional, tanto en objetos de tecnología como en materia cognitiva. ${ }^{2}$

La ciencia actual proscribe todo conocimiento ancestral, porque no puede formular los problemas que plantean estos conocimientos. Los desvaloriza como si ese tipo de conocimiento no tuviera importancia y los estigmatiza con el nombre de superstición, creencia u opinión subjetiva, sin embargo, en un arrebato de doble moral, permite de manera condescendiente la elaboración de constructos (ejemplo: la calidad de vida relacionada con la salud bucal), ${ }^{3}$ la elaboración de patrones de estética (ejemplo: el diseño de sonrisa, el diagnóstico de ortodoncia, que propugna llevar a los pacientes hacia un modelo de estética universal, estándar, postmodernista, determinístico y mecanicista de tipo europeo). ${ }^{4}$

La repercusión de LEDS se ha notado principalmente en la literatura, teniendo como representantes a Mario Vargas Llosa, Gabriel García Márquez y Julio Cortázar. Tuvo también una impronta en la pintura sudamericana, en la que tenemos a maestros como Oswaldo Guayasamín, Francisco de Szyszlo, Fernando Botero, entre otros. En el ámbito de la teología y la ética, tenemos el aporte de LEDS con Leonardo Booff, Gustavo Gutiérrez y Eduardo Arens, que plantean una contracorriente teológica interpretando la doctrina cristiana desde la realidad empobrecida de los pueblos de Sudamérica, de igual forma en la epistemología mundial destaca Mario Bunge, Orlando Fals Borda, Aníbal Quijano y en metodología de la investigación el profesor Roberto Hernández Sampieri y la licenciada Elia B. Pineda, que son autores de los libros más difundidos en investigación.

En cuanto a odontología hubo universidades que fueron faros sudamericanos del desarrollo académico, como la Universidad Nacional Mayor de San Marcos (decana de América), la Universidad de Buenos Aires, Universidad Javeriana, Universidad Nacional Mayor de San Andrés, y su legado se ha visto en la creación

\footnotetext{
* Coordinador de Investigación en Odontología.

$\S$ Docente de Odontopediatría de la Carrera de Odontología.
}

Universidad Católica de Cuenca.

(C) 2017 Universidad Nacional Autónoma de México, [Facultad de Odontología]. Este es un artículo Open Access bajo la licencia CC BY-NC-ND (http://creativecommons.org/licenses/by-nc-nd/4.0/).

Este artículo puede ser consultado en versión completa en http://www.medigraphic.com/facultadodontologiaunam 
de mallas curriculares adaptadas a la realidad local, sin embargo, tras la caída del muro de Berlín con el advenimiento de la globalización y del concepto de aldea mundial, ha surgido un fenómeno de estandarización de patrones en casi todos los desempeños del ser humano, desde la manera de pensar, hasta los modos de actuar. Fenómeno que es sumamente peligroso, porque despersonaliza, quita la identidad de las naciones y pretende tener un modelo eurocéntrico para todo el mundo, dictando lo que es aceptable y lo que no es aceptable. ${ }^{5}$

Sin embargo, ya hay un agotamiento entre los intelectuales del sur respecto al pensamiento eurocéntrico, a raíz de la crisis económica europea que se dio del 2008 al 2014, a causa de las medidas económicas de castigo aplicadas a Grecia, Irlanda, Portugal y España que disminuyeron derechos laborales y sociales, ${ }^{6}$ a pesar de tener cinco siglos enseñándole al mundo economía, política, democracia, da la impresión que Europa ya no tiene más qué enseñar y nos toca inventar el futuro juntos. Sin embargo, su dificultad de aprender del nuevo mundo y reconocernos como pares, como iguales, invita a ser recíprocos. Sus indicadores epidemiológicos (por ejemplo, la experiencia de caries medida mediante CPOD) nos hace pensar que no tienen la solución al problema de mayor prevalencia en el mundo, dado que la caries dental sigue siendo el mayor problema en países industrializados, ya que afecta entre el 60 al $90 \%$ de escolares, según cifras oficiales del director del Programa de Salud Bucal de la Organización Mundial de la Salud. ${ }^{7}$ Esto de ninguna manera significa desconocer el gran legado, social, cultural, económico y científico de los países del norte, todo lo contrario, significa ir de la mano como pares, significa reconocer sus aportes de manera crítica y ajustarla a la realidad, significa hacer valer nuestros conocimientos ancestrales, revalorizar nuestro sentido gregario de la familia y hasta compartir nuestro sentido de la estética en las artes.

El gran avance en las tecnologías alrededor de la rehabilitación oral y de la ortodoncia, que aún no entran en la mayoría de sistemas de salud del mundo (como derecho del paciente que acude al servicio público de salud), hace pensar que hay una deuda social de la odontología con la comunidad, tal como lo propone Roberto Beltrán-Neira, peruano, educador en salud bucal. ${ }^{8}$ Entonces cabe la legítima pregunta: ¿Es realmente oportuna la investigación sobre implantología o sobre brackets de autoligado o sobre enfermedades raras, en países que no han logrado implementar el cepillado como una competencia de autocuidado en los niños? ¿No será que estamos cayendo en el deseo de realizar investigación, sólo para aparecer en los rankings de factor de impacto, por el simple hecho de exigencias institucionales, con fines de acreditación o por simple vanidad, sin tener el macroobjetivo claro, respecto a responder mediante la investigación a las necesidades y prioridades del país?

Actualmente se ha puesto de moda la medicina basada en evidencia (MBE); que es un enfoque puramente positivista, una mirada parcial del proceso salud y enfermedad, con gran influencia de la planificación economicista. ${ }^{9,10}$

Un ejemplo de grandes pasos en Latinoamérica, es la medicina social, que tuvo como principal impulsor al mexicano Juan César García, y al ecuatoriano Miguel Márquez, que tiene su principal punto de enfoque en analizar las inequidades en salud desde el punto de vista de las clases sociales y no desde las características demográficas que suele realizar la salud pública heredada de la epidemiología de John Snow. ${ }^{10}$

Es monumental la tarea que realizaron los argentinos Mario Eduardo Figún y Ricardo Rodolfo Garriño, en su obra "Anatomía odontológica», de la cual aprendimos los odontólogos de Sudamérica en los últimos 20 años.

Es sumamente didáctico el libro de «Neurofisiología de la oclusión» de Enrique Echeverry Guzmán y Gisela Sencherman de Savdie. De igual forma el profesor Arturo Manns que últimamente ha conglomerado los apuntes de los cursos que dictaba en Chile y los ha convertido en un "Manual de oclusión» que brilla por su capacidad didáctica-práctica. Cómo no mencionar al argentino de llegada internacional Fermín Carranza en «Periodoncia clínica» o a Guillermo Romanelli, de la misma nacionalidad.

Otro profesor importante fue Guillermo A. Ries Centeno autor del libro «Cirugía bucal», que ha acompañado a más de cinco generaciones de dentistas en Sudamérica, de quien hemos aprendido la técnica quirúrgica. Basta con revisar las tesis que tratan de caries dental, para ver que el autor más citado es el peruano Gilberto Henostroza-Haro con su libro «La caries dental».

Ecuador es el ejemplo de asistencia a los pacientes con discapacidad; Perú, Venezuela, Colombia, Argentina y Brasil tienen programas gratuitos de prótesis total a personas de extrema pobreza. No podemos dejar de mencionar a Colombia, con su municipio de Antioquia, que ha venido siendo el parangón de la prevención y promoción de la salud bucal en Sudamérica. Cabe también ponerse a pensar en la gran influencia de la escuela biológica brasileña, como la actual meca de la odontología. 


\section{REFERENCIAS}

1. De Zubiría-Samper S. Conferencia investigación acción participativa y epistemologías del sur. Cátedra Libre Martín Baró [Video File]. 2013. [Consultado 2017 Enero 15] [1:31:32 min]. Disponible en: https://www.youtube.com/ watch? $\mathrm{v}=$ lyKekZISnUY

2. Dussel E. Grosfoguel y Dussel - Descolonización y geopolítica del conocimiento - UNAM [Video File]. 2012. [Consultado 2017 Enero 3] [1:39:36 min]. Disponible en: https://www.youtube. com/watch?v=mySCGIdLxQU

3. Gherunpong S, Tsakos G, Sheiham A. Developing and evaluating an oral health-related quality of life index for children; the CHILDOIDP. Community Dent Health. 2004; 21 (2): 161-169.

4. Sarabia-Aguilar JA. Ortopedia maxilar [Internet]. 2009 [Consultado 2017 Enero 30]. Disponible en: http://www.amom. com.mx/amominfo36.htm

5. Eco U. Apocalípticos e integrados. 7a ed. Madrid: Lumen; 1984.
6. Ramonet I. Sadismo económico. Le Monde diplomatique en español. 2012; 201: 1-2.

7. Petersen PE. The World Oral Health Report 2003: continuous improvement of oral health in the 21st century--the approach of the WHO Global Oral Health Programme. Community Dent Oral Epidemiol. 2003; 31 Suppl 1: 3-23.

8. Beltrán-Neira R. Deuda social de la odontología. Rev Estomatol Herediana. 2011; 21 (3): 175-178.

9. Ortega-Calvo M, Cayuela-Domínguez A. Medicina basada en la evidencia: una crítica filosófica sobre su aplicación en atención primaria. Rev Esp Salud Pública. 2002; 76 (2): 115-120.

10. Breilh J. La epidemiología crítica: una nueva forma de mirar la salud en el espacio urbano. Salud Colectiva. 2010; 6 (1): 83-101.

Dirección para correspondencia: Ebingen Villavicencio-Caparó E-mail: ebingen@ hotmail.com 